\title{
Regional Disparities of Rehabilitation Resources for Persons with Disabilities in China: Data from 2014 to 2019
}

\author{
Qi Jing ${ }^{1,2,3,4,5, \dagger}$, Qi Tang ${ }^{1,3,4, \dagger}$, Mei Sun ${ }^{1,3,4}$, Xiaohong Li ${ }^{1,3,4}$, Gang Chen ${ }^{1,3,4}$ and \\ Jun Lu 1,3,4,5,* \\ 1 School of Public Health, Fudan University, Shanghai 200032, China; jingq@wfmc.edu.cn (Q.J.); \\ tangqi@fudan.edu.cn (Q.T.); sunmei@fudan.edu.cn (M.S.); lixh@fudan.edu.cn (X.L.); \\ gchen@shmu.edu.cn (G.C.) \\ 2 School of Management, Weifang Medical University, Weifang 261053, China \\ 3 China Research Center on Disability Issues, Fudan University, Shanghai 200032, China \\ 4 Key Laboratory of Health Technology Assessment, National Health Commission, Fudan University, \\ Shanghai 200032, China \\ 5 China Rehabilitation and Health Institute, Weifang Medical University, Weifang 261053, China \\ * Correspondence: lujun@shmu.edu.cn \\ + These authors contributed equally to this work.
}

Received: 25 August 2020; Accepted: 29 September 2020; Published: 7 October 2020

\begin{abstract}
Although the United Nations' Convention on the Rights of Persons with Disabilities enshrines the right to health for all persons with disabilities (PDs), PDs face health disparities in terms of access to rehabilitation resources, which is important for service supply. This study aimed to explore the trends and distribution of rehabilitation resources for PDs in China from 2014 to 2019, explore the main factors that influence equity, and provide suggestions for policymakers. Data were obtained from the annual China Statistical Bulletin on the Development of Disabled Persons and the database of the China Disabled Persons' Federation. Six types of rehabilitation resources were chosen to measure the trends in allocation and equity. Data on disparities were analyzed based on western, central, and eastern regions. The Health Resource Density Index and Theil Index were calculated to determine the degree and density of unfairness. The findings show a steady increasing trend in the amount of rehabilitation resources in China from 2014 to 2019. The density and equity of allocation of rehabilitation resources have improved greatly in recent years. Regional disparities were principally caused by differences within the regions. Suggestions including expanding investment in rehabilitation resources and developing rehabilitation systems were put forward.
\end{abstract}

Keywords: disparity; rehabilitation resource; disability; HRDI; Theil Index; China

\section{Introduction}

It is estimated that approximately $15 \%$ of the global population has experienced some form of disability, and that between 110 and 190 million people have a severe physical impairment [1]. With the aging of the global population, as well as the prevalence of noncommunicable diseases and unhealthy lifestyles, the number of groups with disabilities will further increase [2,3]. Rehabilitation is a fundamental health service for people with a variety of health conditions, and it addresses the impact of a health condition on a person's life by focusing primarily on improving their functioning and reducing the experience of disability [4]. Sufficient rehabilitation resources and their rational allocation are one of the foundations ensuring the achievement of the United Nation's Sustainable Development Goal 3 (SDG): Ensure healthy lives and promote well-being for all at all ages, universal health coverage, 
and Rehabilitation 2030-Call for action [5]. This goal not only guarantees the fair treatment of the population, including persons with disabilities (PDs), but also follows the Healthy China Strategy 2030, which proposes to "enable all people to have needed, quality, and affordable health services such as prevention, treatment, rehabilitation, and health promotion." This was particularly apparent during the 2020 COVID-19 pandemic, as the UN proposed A Disability-Inclusive Response to COVID-19 to address the specific issues faced by PDs [6]. However, further prioritization of rehabilitation is urgently needed to meet the needs of PDs globally. There exists a global consensus to strengthen rehabilitation in health systems, which includes developing rehabilitation resources.

The United Nations' Convention on the Rights of Persons with Disabilities (CRPD) enshrines the right to health for all PDs. All persons have the right to enjoy the highest attainable standard of health without discrimination on the basis of disability, and to have access to high-quality health services, including rehabilitation [7]. Often, however, PDs face health disparities in areas such as service availability, affordability, and quality of physical accessibility of resources, reflecting broader issues of disability inclusion. Furthermore, in our opinion, PDs from low- and middle-income countries should be given more attention due to their poor economic circumstances and vulnerability. As the world's second largest economy, China is still a middle-income country with regional disparities relevant to specific economic and social development [8]. To improve the accessibility and availability of rehabilitation services for PDs, the government should take measures to allocate the health or rehabilitation resources that address the political commitment of social equity.

As the aging of China's population continues, the prevalence of chronic diseases and the total number of PDs increase; thus, the demand for rehabilitation is growing rapidly. By the end of 2019, China's elderly population (aged 60 and above) had reached 254 million, accounting for $18.1 \%$ of the total population of China [9] and $24.3 \%$ of the world's elderly population, ranking first in the world (calculated by the authors). According to the China Disabled Persons' Federation (CDPF) database, the number of registered persons with disabilities (RPDs) in China, which are categorized into four levels (Grades 1-4, with Grade 1 representing the most severe disability), reached more than 36.8 million in 2019. Under the Sixth National Population Census and the second national sample survey of PDs, it was estimated that the actual total number of PDs in China had reached 85 million, of whom nearly 50 million had rehabilitation needs [10].

Growing interest in inequality has brought many discussions on the subject into the public realm. However, few studies concentrate on rehabilitation resource disparities for PDs. Instead, the research has deeply explored the following three topics: (1) specific rehabilitation issues such as cardiac rehabilitation [11], exercise-based rehabilitation for non-communicable diseases [12], community-based rehabilitation resources [13], etc.; (2) health resource disparities including the perspectives of urban and rural communities [14], specific topics such as workforce [15] (physicians [16]), facilities [17] (institutions [18]), services, etc.; and (3) research methods on disparity or equity, for example the Theil Index [19], Gini-coefficient [20], Atkinson index [21], etc. Owing to this lack of academic concern for rehabilitation resource disparities for PDs, we propose the following research question: What are the trends, situations, disparities, and main influencing factors regarding rehabilitation resources for PDs in China? As the Theil Index is more sensitive in evaluating the equality of resource allocation, we aimed to explore the trends and distribution of rehabilitation resources for PDs in China from 2014 to 2019. Further, we investigated the main factors that influence equity or disparity and offer suggestions for policymakers. The data resources are the annual China Statistical Bulletin on the Development of Disabled Persons and the CDPF database. Six indicators were chosen to measure the trends in equity of rehabilitation resource allocation in China: Rehabilitation Institutions (RIs), Staff in RIs, Professionals in RIs, Total Completed Projects of Rehabilitation Service Facilities (RSFs), Total Construction Area of Projects Completed on RSFs, and the Total Investment of Projects Completed on RSFs. Regional disparities were analyzed by comparing the western, central, and eastern regions using the Theil Index and Health Resource Density Index (HRDI). 


\section{Materials and Methods}

This study aimed to explore the trends and distribution of rehabilitation resources for PDs in China, explore the main factors that influence equity, and provide suggestions for policymakers. Then, the results may draw more attention to rehabilitation resource disparity. Regarding the limitation that the national statistics system does not include specific rehabilitation resources and study purposes, the rehabilitation resources data mainly come from the CDPF, which is a non-governmental and a national umbrella organization for persons with diverse disabilities (mainly visual, hearing, speech, physical, intellectual, and mental disabilities). The rehabilitation resources excluded medical resources such as hospitals, medical facilities, and workforce. In addition, it is estimated that the actual number of PDs is much higher than the RPDs who are registered with CDPF. To ensure a comparative analysis, this research used the official statistics of RPDs. Based on to data availability, the national analysis period was 2014-2019 and the regional analysis period was 2014-2018.

\subsection{Data Resources and Regional Division}

In this study, we collected the relevant data from the annual China Statistical Bulletin on the Development of Disabled Persons (2014-2019) and the CDPF database (2014-2018). All data are openly accessible on the CDPF's public website. To analyze regional disparities, the 31 provinces, autonomies, and municipalities of mainland China were divided into three regions. According to geographical position and gross domestic product per capita, the three regions are described as western, central, and eastern, which represent undeveloped, developing, and developed regions in mainland China, respectively. Beijing, Tianjin, Hebei, Liaoning, Shanghai, Jiangsu, Zhejiang, Fujian, Shandong, Guangdong, and Hainan belong to the eastern region. Shanxi, Jilin, Heilongjiang, Anhui, Jiangxi, Henan, Hubei, and Hunan belong to the central region. Inner Mongolia, Guangxi, Chongqing, Sichuan, Guizhou, Yunnan, Tibet, Shaanxi, Gansu, Qinghai, Ningxia, and Xinjiang belong to the western region.

\subsection{Measurements (Indicators)}

Generally, health resource-related indicators include three basic aspects: workforce, financing, and property. After scanning the database, we chose six indicators: Staff and Professionals in RIs to represent the rehabilitation workforce; Total Completed Projects and Total Investment of Projects Completed on RSF to represent financing; and Rehabilitation Institution and Total Construction Area of Projects Completed on RSF to represent property. Then, we described and analyzed the six indicators. The indicator descriptions are as follows: (1) Staff in RIs refers to the persons who work at rehabilitation institutions, including professionals (rehabilitation physicians, nurses, therapists, technicians, etc.), managerial personnel (responsible for management and coordination), and other support personnel; (2) Total Completed Projects on RSFs refers to tailored construction and services projects, such as the establishment of specific rehabilitation training centers, and Total Investment of Projects Completed on RSFs refers to the annual investment on projects; and (3) Rehabilitation Institutions refers to institutions for different types of disabilities, such as visual, hearing and speech, physical, intellectual, mental, and autism in children. In this study, we included assistive technology institutions in RIs in statistics. Total Construction Area of Projects Completed on RSFs refers to the scale of the construction for projects completed on RSFs yearly.

\subsection{Main Analysis Methods}

\subsubsection{Health Resource Density Index}

HRDI was used to assess equity both in demographic and geographic dimensions. The HRDI was combined with the data to demonstrate differences in rehabilitation resources for PDs in 31 provinces and municipalities. In addition, the HRDI could avoid bias and influences caused by a single aspect of 
population or geographic area [22]. The value of HRDI equals the geometric mean of rehabilitation resources per 10,000 RPDs and per 10,000 square kilometers. The formula of HRDI is as follows:

$$
H R D I=\sqrt{\left(r_{i} / p_{i}\right) \times\left(r_{i} / a_{i}\right)},
$$

In the above formula, $r_{i}$ represents the rehabilitation resource, $p_{i}$ represents RPDs, and $a_{i}$ represents the square of the unit $I$.

\subsubsection{Theil Index}

The Theil Index, named for the researcher who first proposed it in 1967 [23], is an inequality measure related to Shannon entropy and a relative indicator that ranges from 0 to 1 . A low Theil value means low inequality, while high values represent a high deviation from an equal distribution. A Theil Index of 0 indicates perfect equality and that every region has the correct proportion of resources for the population. Conversely, a standardized Theil Index value of 1 represents a state of perfect inequality, where one region has all the variables of interest. The Theil Index has been tested in a series of areas, such as the economic [24], energy [25], and health sectors [26], to evaluate equity and disparity. The formula of the Theil Index is as follows:

$$
T=\sum_{i=1}^{n} p_{i} \ln \frac{p_{i}}{y_{i}} .
$$

where $p_{i}$ represents the proportion of the unit RPDs accounting for the aggregation in one region and $y_{i}$ represents the unit's rehabilitation resource accounting for the aggregation in one region.

The Theil Index can be decomposed into two components: to describe inequality "within" and "in between" subgroups. The formulas are as follows:

$$
\begin{gathered}
T_{\mathrm{w}}=\sum_{g=1}^{k} p_{g} t_{g}, \\
T_{\mathrm{b}}=\sum_{g=1}^{k} p_{g} \ln \frac{p_{g}}{y_{g}}, \\
T=T_{\mathrm{w}}+T_{\mathrm{b}} .
\end{gathered}
$$

$T_{w}$ represents the degree of rehabilitation resource allocation fairness in a targeted region; $T_{b}$ represents the degree of rehabilitation resource allocation equity between the different regions; and $p_{g}$ and $y_{g}$ have the same meaning as $p_{i}$ and $y_{i}$ above.

\section{Results}

\subsection{Trends of Rehabilitation Resource Allocation from 2014 to 2019}

Changes in the amount of rehabilitation resources for PDs are shown in Table 1. Generally, the rehabilitation resources for PDs in China have been increasing in recent years. The RPDs figure grew from 29.47 million to 36.82 million, and the rehabilitation resources of the six indicators per 10,000 RPDs generally increased from 2014 to 2019. The total investment and construction area of projects completed on RSFs for PDs, which increased in 2019, were triple those of 2014. Per 10,000 RPDs, the number of RIs, staff, professionals, and completed projects rose $41.38 \%, 13.00 \%, 18.75 \%$, and $64.11 \%$, respectively. In terms of density, the workforce for rehabilitation per 10,000 RPDs decreased in 2019 when compared to 2014 (staff, $-9.55 \%$; professionals, $-4.95 \%$ ). 
Table 1. Rehabilitation resources for PDs in China from 2014 to 2019 a

\begin{tabular}{|c|c|c|c|c|c|c|c|c|c|c|c|c|c|}
\hline \multirow[t]{2}{*}{ Year } & \multirow{2}{*}{$\begin{array}{c}\begin{array}{c}\text { Registered } \\
\text { Persons } \\
\text { with } \\
\text { Disabilities }\end{array} \\
\text { 10,000 Persons }\end{array}$} & \multicolumn{2}{|c|}{$\begin{array}{l}\text { RIs for } \\
\text { PDs }\end{array}$} & \multicolumn{2}{|c|}{$\begin{array}{l}\text { Staff in } \\
\text { RIs }\end{array}$} & \multicolumn{2}{|c|}{$\begin{array}{l}\text { Professionals in } \\
\text { RIs }\end{array}$} & \multicolumn{2}{|c|}{$\begin{array}{c}\text { Total Completed } \\
\text { Projects of RSFs for PDs }\end{array}$} & \multicolumn{2}{|c|}{$\begin{array}{c}\text { Total Construction Area } \\
\text { of Accumulated Projects } \\
\text { Completed on RSFs } \\
\text { for PDs }\end{array}$} & \multicolumn{2}{|c|}{$\begin{array}{l}\text { Total Investment of } \\
\text { Projects Completed on } \\
\text { RSFs for PDs }\end{array}$} \\
\hline & & Number & $\begin{array}{l}\text { per } 10,000 \\
\text { RPDs }\end{array}$ & Number & $\begin{array}{l}\text { per } 10,000 \\
\text { RPDs }\end{array}$ & Number & $\begin{array}{l}\text { per } 10,000 \\
\text { RPDs }\end{array}$ & Number & $\begin{array}{l}\text { per } 100,000 \\
\text { RPDs }\end{array}$ & $10,000 \mathrm{~m}^{2}$ & $\begin{array}{l}\mathrm{m}^{2} \text { per } \\
\text { RPDs }\end{array}$ & $\begin{array}{l}100,000,000 \\
\text { Yuan }\end{array}$ & $\begin{array}{l}\text { Yuan per } \\
\text { RPDs }\end{array}$ \\
\hline $2014^{\mathrm{b}}$ & 2947.0 & 6914 & 2.35 & 233,631 & 79.28 & 160,000 & 54.29 & 613 & 2.08 & 130.01 & 0.04 & 40.38 & 137.02 \\
\hline 2015 & 3145.7 & 7111 & 2.26 & 232,370 & 73.87 & 159,563 & 50.72 & 682 & 2.17 & 165.65 & 0.05 & 51.27 & 162.98 \\
\hline 2016 & 3219.4 & 7858 & 2.44 & 222,594 & 69.14 & 149,446 & 46.42 & 762 & 2.37 & 213.40 & 0.07 & 65.70 & 204.08 \\
\hline 2017 & 3404.0 & 8334 & 2.45 & 245,822 & 72.22 & 164,264 & 48.26 & 833 & 2.45 & 261.40 & 0.08 & 80.80 & 237.37 \\
\hline 2018 & 3566.2 & 9036 & 2.53 & 250,469 & 70.23 & 176,471 & 49.48 & 914 & 2.56 & 344.90 & 0.10 & 111.20 & 311.82 \\
\hline $2019^{b}$ & 3681.7 & 9775 & 2.66 & 264,000 & 71.71 & 190,000 & 51.61 & 1006 & 2.73 & 414.20 & 0.11 & 132.20 & 359.07 \\
\hline
\end{tabular}

a Abbreviations: RIs, Rehabilitation Institution; PDs, Persons with Disabilities; RPD, Registered Persons with Disabilities; RSFs, Rehabilitation Service Facilities (this information is identical for the following tables). ${ }^{b}$ The data came from two resources. If the provincial database lacked the data, we chose the China Statistical Bulletin on the Development of Disabled Persons as the data source; however, the numbers may not be as accurate as the official website. 


\subsection{Regional Distribution of Rehabilitation Resources for PDs in 2018}

To further understand the rehabilitation resource distribution in China, we calculated the rehabilitation resources per 10,000 RPDs and per 10,000 km² in 2018 (the provincial data have been updated only to 2018). The results are shown in Tables 2 and 3, respectively. Generally, when compared to other provinces, eastern areas such as Shanghai, Guangdong, and Shandong, central areas including Shanxi, and western areas such as Chongqing had higher distribution values, both per 10,000 RPDs and geographically on all types of rehabilitation resources.

Table 2. Regional distribution per 10,000 RPDs of rehabilitation resources for PDs in China in 2018.

\begin{tabular}{|c|c|c|c|c|c|c|c|}
\hline Region & Area & $\begin{array}{l}\text { RIs for } \\
\text { PDs }\end{array}$ & $\begin{array}{l}\text { Staff in } \\
\text { RIs }\end{array}$ & $\begin{array}{l}\text { Professionals } \\
\text { in RIs }\end{array}$ & $\begin{array}{l}\text { Projects of } \\
\text { RSFs for } \\
\text { PDs }\end{array}$ & $\begin{array}{l}\text { Construction } \\
\text { Area of Projects } \\
\text { of RSFs for PDs }\end{array}$ & $\begin{array}{l}\text { Investment of } \\
\text { Accumulated } \\
\text { Projects of RSFs } \\
\text { for PDs }\end{array}$ \\
\hline \multicolumn{2}{|c|}{ National } & 2.53 & 70.23 & 49.48 & 0.26 & 967.24 & 311.69 \\
\hline Eastern & Beijing & 2.41 & 71.76 & 49.28 & 0.57 & 251.38 & 157.31 \\
\hline Eastern & Tianjin & 2.64 & 66.10 & 43.23 & 2.97 & 555.42 & 322.99 \\
\hline Eastern & Hebei & 2.28 & 66.46 & 47.02 & 0.48 & 306.89 & 90.66 \\
\hline Eastern & Liaoning & 3.55 & 91.49 & 64.53 & 1.89 & 932.42 & 224.51 \\
\hline Eastern & Shanghai & 18.96 & 158.53 & 83.41 & 0.89 & 1778.26 & 798.96 \\
\hline Eastern & Jiangsu & 2.68 & 84.18 & 59.70 & 3.94 & 1523.05 & 608.03 \\
\hline Eastern & Zhejiang & 1.62 & 50.70 & 35.10 & 3.15 & 2159.14 & 859.03 \\
\hline Eastern & Fujian & 2.96 & 67.51 & 45.80 & 23.68 & 680.43 & 181.08 \\
\hline Eastern & Shandong & 2.49 & 98.48 & 76.39 & 4.68 & 2882.29 & 832.23 \\
\hline Eastern & Guangdong & 4.75 & 161.04 & 114.65 & 2.98 & 1271.95 & 422.12 \\
\hline Eastern & Hainan & 1.91 & 59.69 & 45.40 & 2.24 & 622.05 & 208.19 \\
\hline Central & Shanxi & 3.39 & 101.49 & 75.37 & 4.36 & 1198.01 & 328.86 \\
\hline Central & Jilin & 3.46 & 131.96 & 85.54 & 1.18 & 464.38 & 185.25 \\
\hline Central & Heilongjiang & 2.89 & 62.84 & 45.30 & 0.89 & 646.21 & 189.15 \\
\hline Central & Anhui & 1.33 & 32.60 & 25.00 & 1.18 & 690.37 & 247.82 \\
\hline Central & Jiangxi & 1.88 & 53.51 & 33.22 & 1.16 & 1065.00 & 187.25 \\
\hline Central & Henan & 1.41 & 50.14 & 39.41 & 0.88 & 595.06 & 137.87 \\
\hline Central & Hubei & 1.39 & 47.28 & 31.46 & 0.91 & 445.25 & 137.85 \\
\hline Central & Hunan & 2.32 & 70.20 & 50.03 & 2.08 & 563.40 & 124.32 \\
\hline Western & Inner Mongolia & 2.57 & 61.81 & 39.79 & 2.32 & 1137.30 & 399.03 \\
\hline Western & Guangxi & 2.68 & 64.32 & 45.92 & 0.74 & 479.01 & 126.29 \\
\hline Western & Chongqing & 3.02 & 84.58 & 56.83 & 1.48 & 926.10 & 346.84 \\
\hline Western & Sichuan & 1.01 & 38.57 & 26.02 & 1.67 & 750.78 & 320.68 \\
\hline Western & Guizhou & 1.60 & 57.70 & 38.56 & 0.74 & 520.67 & 132.21 \\
\hline Western & Yunnan & 1.84 & 49.73 & 34.64 & 0.50 & 306.64 & 85.89 \\
\hline Western & Tibet & 0.58 & 6.12 & 3.79 & 12.62 & 2163.99 & 804.14 \\
\hline Western & Shaanxi & 2.64 & 92.83 & 69.87 & 2.95 & 643.15 & 192.92 \\
\hline Western & Gansu & 1.65 & 39.47 & 27.58 & 2.04 & 1051.00 & 254.01 \\
\hline Western & Qinghai & 1.72 & 22.44 & 13.41 & 3.32 & 1875.73 & 752.88 \\
\hline Western & Ningxia & 1.27 & 24.05 & 16.54 & 2.55 & 2176.88 & 887.83 \\
\hline Western & Xinjiang & 3.15 & 56.71 & 40.00 & 5.68 & 1537.16 & 432.98 \\
\hline
\end{tabular}

From the perspective of per 10,000 RPDs, we could acquire a basic understanding of provincial resource distribution and density. In terms of the rehabilitation institutions for PDs, the majority of the values were concentrated below 5, except for Shanghai, which reached almost 19. Guangdong had the highest value of staff and professionals in distribution of RIs with more than 100 persons per 10,000 RPDs. Additionally, we found extreme disparities between the highest and lowest values: the number of RIs per 10,000 RPDs in Shanghai (18.96) was 30 times higher than that in Tibet (0.58), while the eastern regions were 1.8 times higher than the western regions.

Regarding the aspect of regional distribution per $10,000 \mathrm{~km}^{2}$, the resources were concentrated in five eastern areas (Shanghai, Beijing, Tianjin, Guangdong, Jiangsu, and Shandong), all of which ranked among the top 10 in almost all six indicators. The geographic distribution gap was larger than that of the demographic. For the other indicators, and apart from the projects of RSFs for PDs, Shanghai was the highest ranked and Tibet was the lowest. 
Table 3. Regional distribution per 10,000 km² of rehabilitation resources for PDs in China in 2018.

\begin{tabular}{|c|c|c|c|c|c|c|c|}
\hline Region & Area & $\begin{array}{l}\text { RIs for } \\
\text { PDs }\end{array}$ & $\begin{array}{c}\text { Staff in } \\
\text { RIs }\end{array}$ & $\begin{array}{l}\text { Professionals } \\
\text { inRIs }\end{array}$ & $\begin{array}{l}\text { Project of } \\
\text { RSF for PDs }\end{array}$ & $\begin{array}{c}\text { Construction } \\
\text { Area of } \\
\text { Accumulated } \\
\text { Projects of RSFs } \\
\text { for PDs }\end{array}$ & $\begin{array}{l}\text { Investment of } \\
\text { Accumulated } \\
\text { Projects of RSFs } \\
\text { for PDs }\end{array}$ \\
\hline \multicolumn{2}{|c|}{ National } & 9.41 & 260.91 & 183.82 & 0.95 & 3593.08 & 1157.86 \\
\hline Eastern & Beijing & 77.44 & 2301.22 & 1580.49 & 1.83 & 8061.59 & 5044.94 \\
\hline Eastern & Tianjin & 74.17 & 1856.67 & 1214.17 & 8.33 & 15600.00 & 9071.67 \\
\hline Eastern & Hebei & 22.83 & 665.78 & 471.03 & 0.48 & 3074.21 & 908.16 \\
\hline Eastern & Liaoning & 25.41 & 654.19 & 461.42 & 1.35 & 6666.96 & 1605.29 \\
\hline Eastern & Shanghai & 1700.00 & 14215.87 & 7479.37 & 7.94 & 159463.49 & 71645.87 \\
\hline Eastern & Jiangsu & 40.58 & 1275.84 & 904.76 & 5.97 & 23083.30 & 9215.32 \\
\hline Eastern & Zhejiang & 20.24 & 632.02 & 437.52 & 3.93 & 26915.03 & 10708.42 \\
\hline Eastern & Fujian & 22.57 & 514.33 & 348.93 & 18.04 & 5183.77 & 1379.54 \\
\hline Eastern & Shandong & 35.72 & 1411.72 & 1095.06 & 6.71 & 41316.72 & 11929.78 \\
\hline Eastern & Guangdong & 40.79 & 1384.03 & 985.31 & 2.56 & 10931.61 & 3627.86 \\
\hline Eastern & Hainan & 9.60 & 300.85 & 228.81 & 1.13 & 3135.31 & 1049.35 \\
\hline Central & Shanxi & 20.87 & 624.38 & 463.69 & 2.68 & 7370.64 & 2023.26 \\
\hline Central & Jilin & 15.69 & 598.99 & 388.26 & 0.53 & 2107.90 & 840.88 \\
\hline Central & Heilongjiang & 6.83 & 148.52 & 107.06 & 0.21 & 1527.40 & 447.08 \\
\hline Central & Anhui & 16.92 & 413.99 & 317.56 & 1.50 & 8767.74 & 3147.35 \\
\hline Central & Jiangxi & 12.58 & 358.42 & 222.53 & 0.78 & 7134.03 & 1254.34 \\
\hline Central & Henan & 23.05 & 822.10 & 646.23 & 1.44 & 9757.31 & 2260.60 \\
\hline Central & Hubei & 11.51 & 390.32 & 259.71 & 0.75 & 3675.47 & 1137.95 \\
\hline Central & Hunan & 18.93 & 572.29 & 407.84 & 1.70 & 4593.06 & 1013.48 \\
\hline Western & Inner Mongolia & 1.78 & 42.83 & 27.57 & 0.16 & 788.12 & 276.52 \\
\hline Western & Guangxi & 15.28 & 366.16 & 261.41 & 0.42 & 2726.94 & 718.94 \\
\hline Western & Chongqing & 32.16 & 899.88 & 604.61 & 1.58 & 9853.28 & 3690.23 \\
\hline Western & Sichuan & 5.72 & 218.27 & 147.26 & 0.95 & 4249.03 & 1814.90 \\
\hline Western & Guizhou & 11.01 & 398.07 & 266.00 & 0.51 & 3592.28 & 912.15 \\
\hline Western & Yunnan & 6.52 & 175.82 & 122.46 & 0.18 & 1084.14 & 303.66 \\
\hline Western & Tibet & 0.05 & 0.51 & 0.32 & 0.11 & 181.46 & 67.43 \\
\hline Western & Shaanxi & 17.41 & 612.69 & 461.19 & 1.95 & 4244.99 & 1273.33 \\
\hline Western & Gansu & 3.03 & 72.65 & 50.76 & 0.38 & 1934.56 & 467.54 \\
\hline Western & Qinghai & 0.43 & 5.61 & 3.35 & 0.08 & 468.75 & 188.15 \\
\hline Western & Ningxia & 4.52 & 85.39 & 58.73 & 0.90 & 7728.01 & 3151.84 \\
\hline Western & Xinjiang & 1.10 & 19.80 & 13.96 & 0.20 & 536.65 & 151.16 \\
\hline
\end{tabular}

\subsection{Regional HRDI of Rehabilitation Resources for PDs in 2018}

To avoid the bias and influences caused by a single aspect of population or geographical area, HRDI was applied to assess equity both in demographic and geographic dimensions. We calculated formula (1), which indicated that the 31 provinces and municipalities had large regional disparities. The highest HRDI in all indicators was at least 30 times higher than the lowest. The largest disparity regarding HRDI was evident within the RI indicator. Geographically, the eastern regions' HRDI was 4.2 and 1.8 times higher than those of the western and central areas, respectively. Shanghai ranked first in five indicators, while Fujian ranked first in one indicator. Tianjin, Guangdong, Beijing, Jiangsu, Chongqing, Liaoning, Shandong, Shanxi, etc. ranked within the top 15 HRDI.

\subsection{Theil Index of Rehabilitation Resources Allocation Based on RPDs}

The results shown in Tables 2-4 present the context of provincial rehabilitation resources for allocation to PDs, from which we noticed a large difference between the regions. Generally, the share of rehabilitation resources in the eastern regions is more than that in the central and western regions. During further investigation on the extent of the regional disparities, the Theil Index was calculated in the three regions from 2016 to 2018 (Figure 1). Excluding the data regarding staff and professionals, the regional data of the remaining four indicators were changed or missing. The Theil Index indicated that the data on RIs, staff, and professionals were from 2016 to 2018, and that the other three indicators were from 2017 to 2018. The Theil Index of projects of RSFs was significantly higher from 2016 to 2018 than those of other kinds of resources. In 2018, it decreased from approximately 0.55 to 0.43 , which was still higher than those of RIs (0.15), staff (0.09), professionals (0.09), construction area (0.20), and investment of the projects (0.25). Excluding the staff and professionals, the Theil Index of all the 
rehabilitation resources showed a general downward trend in the most recent three years. The whole Theil Index was divided into three regions. The following figure could reflect the changes of the Theil Index during 2016-2018.

Table 4. Regional HRDI of rehabilitation resources for PDs in China in 2018.

\begin{tabular}{|c|c|c|c|c|c|c|c|}
\hline Region & Area & $\begin{array}{l}\text { RIs for } \\
\text { PDs }\end{array}$ & $\begin{array}{l}\text { Staff in } \\
\text { RIs }\end{array}$ & $\begin{array}{l}\text { Professionals } \\
\text { in RIs }\end{array}$ & $\begin{array}{l}\text { Projects of } \\
\text { RSF for PDs }\end{array}$ & $\begin{array}{c}\text { Construction } \\
\text { Area of } \\
\text { Accumulated } \\
\text { Projects of RSFs } \\
\text { for PDs }\end{array}$ & $\begin{array}{l}\text { Investment of } \\
\text { Accumulated } \\
\text { Projects of RSFs } \\
\text { for PDs }\end{array}$ \\
\hline \multicolumn{2}{|c|}{ National } & 4.88 & 135.37 & 95.38 & 0.49 & 1864.23 & 600.74 \\
\hline Eastern & Beijing & 13.67 & 406.36 & 279.09 & 1.02 & 1423.55 & 890.86 \\
\hline Eastern & Tianjin & 13.99 & 350.33 & 229.10 & 4.97 & 2943.56 & 1711.73 \\
\hline Eastern & Hebei & 7.21 & 210.36 & 148.82 & 0.48 & 971.30 & 286.94 \\
\hline Eastern & Liaoning & 9.50 & 244.65 & 172.56 & 1.60 & 2493.27 & 600.34 \\
\hline Eastern & Shanghai & 179.52 & 1501.21 & 789.83 & 2.65 & 16839.47 & 7565.86 \\
\hline Eastern & Jiangsu & 10.42 & 327.72 & 232.40 & 4.85 & 5929.34 & 2367.11 \\
\hline Eastern & Zhejiang & 5.73 & 179.01 & 123.92 & 3.52 & 7623.20 & 3032.97 \\
\hline Eastern & Fujian & 8.18 & 186.34 & 126.42 & 20.67 & 1878.08 & 499.81 \\
\hline Eastern & Shandong & 9.43 & 372.87 & 289.23 & 5.61 & 10912.69 & 3150.93 \\
\hline Eastern & Guangdong & 13.91 & 472.10 & 336.10 & 2.76 & 3728.86 & 1237.49 \\
\hline Eastern & Hainan & 4.28 & 134.00 & 101.92 & 1.59 & 1396.54 & 467.41 \\
\hline Central & Shanxi & 8.41 & 251.72 & 186.94 & 3.42 & 2971.55 & 815.70 \\
\hline Central & Jilin & 7.36 & 281.14 & 182.24 & 0.79 & 989.38 & 394.68 \\
\hline Central & Heilongjiang & 4.44 & 96.60 & 69.64 & 0.43 & 993.49 & 290.80 \\
\hline Central & Anhui & 4.75 & 116.17 & 89.11 & 1.33 & 2460.29 & 883.17 \\
\hline Central & Jiangxi & 4.86 & 138.48 & 85.98 & 0.95 & 2756.40 & 484.64 \\
\hline Central & Henan & 5.69 & 203.02 & 159.59 & 1.12 & 2409.61 & 558.27 \\
\hline Central & Hubei & 4.01 & 135.85 & 90.39 & 0.83 & 1279.25 & 396.06 \\
\hline Central & Hunan & 6.63 & 200.43 & 142.84 & 1.88 & 1608.64 & 354.95 \\
\hline Western & Inner Mongolia & 2.14 & 51.45 & 33.12 & 0.61 & 946.75 & 332.17 \\
\hline Western & Guangxi & 6.40 & 153.47 & 109.56 & 0.56 & 1142.91 & 301.32 \\
\hline Western & Chongqing & 9.86 & 275.88 & 185.36 & 1.53 & 3020.78 & 1131.34 \\
\hline Western & Sichuan & 2.40 & 91.75 & 61.90 & 1.26 & 1786.08 & 762.89 \\
\hline Western & Guizhou & 4.19 & 151.55 & 101.27 & 0.61 & 1367.63 & 347.26 \\
\hline Western & Yunnan & 3.47 & 93.51 & 65.13 & 0.30 & 576.58 & 161.50 \\
\hline Western & Tibet & 0.17 & 1.77 & 1.10 & 1.16 & 626.63 & 232.86 \\
\hline Western & Shaanxi & 6.78 & 238.49 & 179.51 & 2.39 & 1652.32 & 495.63 \\
\hline Western & Gansu & 2.23 & 53.55 & 37.42 & 0.88 & 1425.91 & 344.61 \\
\hline Western & Qinghai & 0.86 & 11.22 & 6.70 & 0.53 & 937.68 & 376.37 \\
\hline Western & Ningxia & 2.40 & 45.32 & 31.17 & 1.52 & 4101.58 & 1672.81 \\
\hline Western & Xinjiang & 1.86 & 33.51 & 23.63 & 1.06 & 908.25 & 255.83 \\
\hline
\end{tabular}

The Theil Index of the eastern regions showed a higher value than the central or western regions. In terms of the rehabilitation workforce, the Theil Index of staff and professionals in RIs presented a first decreasing and then increasing trend (both 0.09 in 2018), but their values were obviously lower than those of the other four indicators, which were more than 0.15. Apart from the five other indicators, the western region's Theil Index for professionals in RIs for PDs was higher than that of the central and eastern regions: the western region was the least equitable with regard to workforce distribution. Compared to personnel, fairness in the allocation of other rehabilitation resources clearly improved as the values decreased.

As shown in Table 5, the between-group contribution rates were less than $35 \%$ in every indicator and year, they and were lower than the proportion of within-group contribution rates. Except for the investment of completed projects in RSFs for PDs, the between-group contributions of other rehabilitation resources showed a decreasing trend. That is, the main contribution for the total Theil Index, which represented equity, was the within-group Theil Index. 


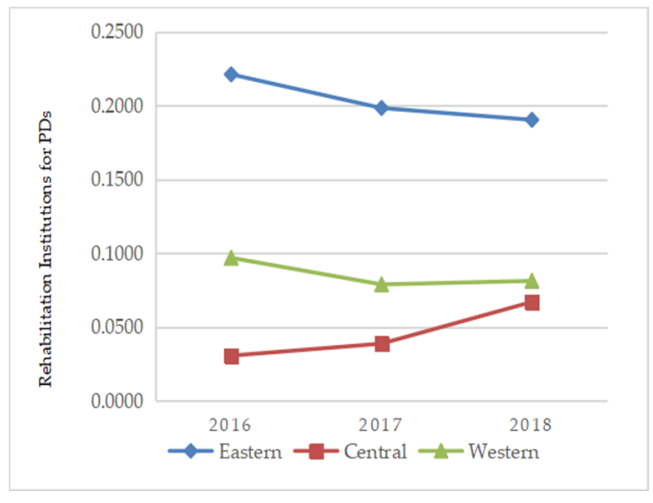

(a)

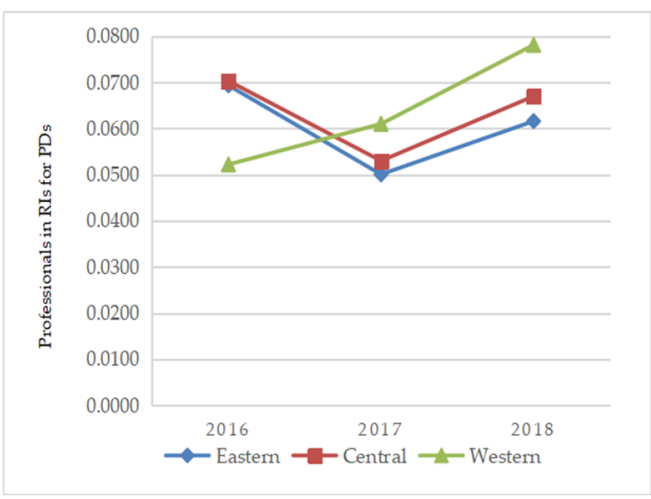

(c)

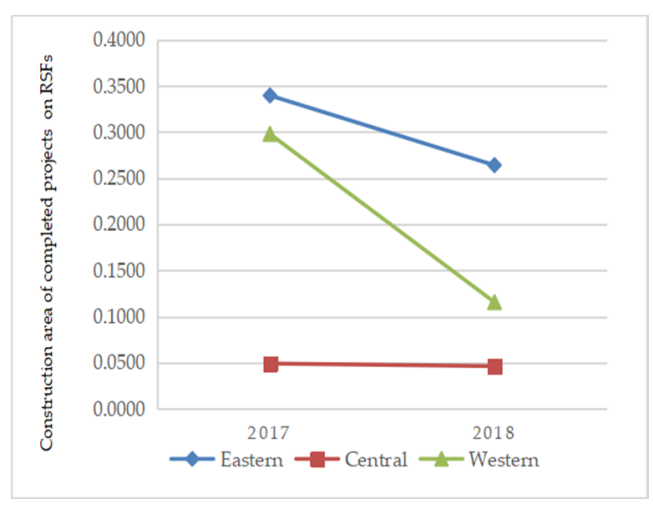

(e)

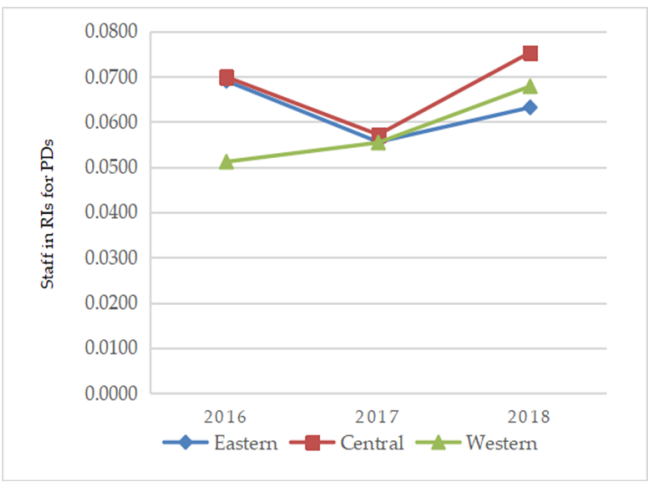

(b)

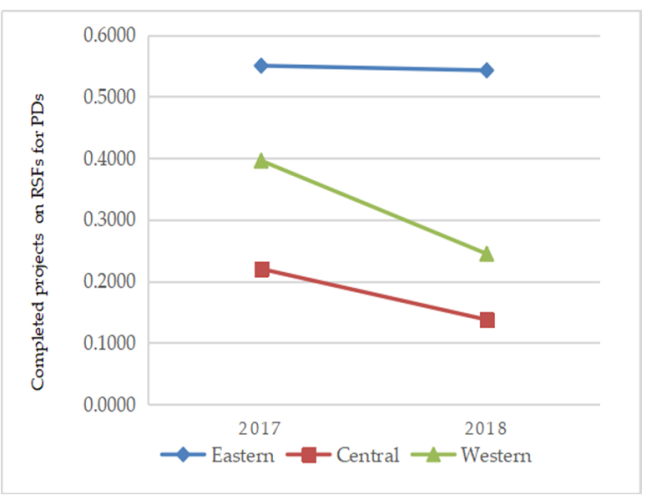

(d)

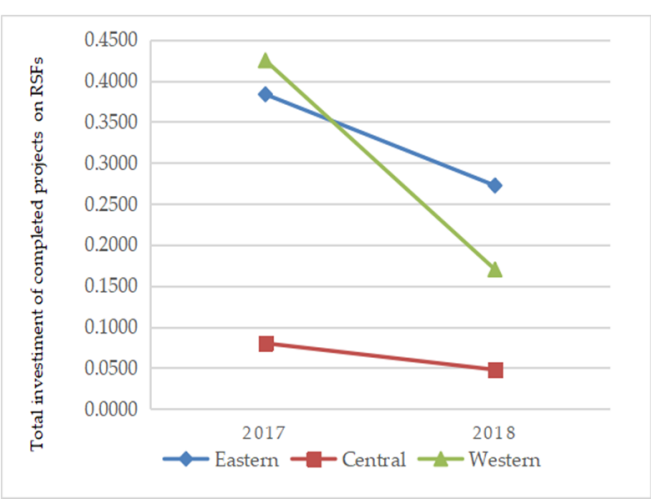

(f)

Figure 1. The regional Theil Index trends of six types of rehabilitation resources (which showed from (a) to (f) respectively) in China from 2016 to 2018. (a) Theil index values of RIs for PDs from 2016 to 2018 in the three regions; (b) Theil index values of staffs in RIs for PDs from 2016 to 2018 in the three regions; (c) Theil index values of professionals in RIs for PDs from 2016 to 2018 in the three regions; (d) Theil index values of completed Projects on RSFs for PDs from 2017 to 2018 in the three regions; (e) Theil index values of construction area of completed projects on RSFs from 2017 to 2018 in the three regions; (f) Theil index values of total investment of completed projects on RSFs from 2017 to 2018 in the three regions. 
Table 5. Theil Index and contribution rates of rehabilitation resources for PDs in China.

\begin{tabular}{ccccc}
\hline Rehabilitation Resource & Year & Theil Index & Within-Group & Between-Group \\
\hline \multirow{3}{*}{ RIs for PDs } & 2016 & 0.1795 & $65.90 \%$ & $34.10 \%$ \\
& 2017 & 0.1529 & $69.66 \%$ & $30.34 \%$ \\
& 2018 & 0.1532 & $74.29 \%$ & $25.71 \%$ \\
\hline Staff in RIs & 2016 & 0.0921 & $68.75 \%$ & $31.25 \%$ \\
& 2017 & 0.0800 & $70.00 \%$ & $30.00 \%$ \\
& 2018 & 0.0921 & $74.64 \%$ & $25.36 \%$ \\
\hline Professionals in RIs & 2016 & 0.1016 & $68.75 \%$ & $31.25 \%$ \\
& 2017 & 0.0825 & $70.00 \%$ & $30.00 \%$ \\
\hline Projects of RSFs for PDs & 2018 & 0.0923 & $74.64 \%$ & $25.36 \%$ \\
\hline Construction area of completed & 2017 & 0.5454 & $71.73 \%$ & $28.27 \%$ \\
projects of RSFs for PDs & 2018 & 0.4275 & $72.75 \%$ & $27.25 \%$ \\
\hline Investment of completed projects & 2018 & 0.3388 & $68.09 \%$ & $31.91 \%$ \\
of RSFs for PDs & 2018 & 0.1980 & $72.39 \%$ & $27.61 \%$ \\
\hline
\end{tabular}

\section{Discussion}

Rehabilitation is a fundamental health service for people with a variety of health conditions, and primarily focuses on improving their ability to function well in society and on reducing the impact of disability. This was a nationwide study that comprehensively evaluated the trend of rehabilitation resources allocation tailored for PDs in China. We found a steady rising trend in the total amount of rehabilitation resources in China, annually per 10,000 RPDs and per 10,000 km². Although the United Nations' CRPD enshrines the right to health for all PDs, PDs face health disparities in terms of access to rehabilitation services. However, our findings indicate that the opportunities for PDs to obtain rehabilitation services are expanding. With the development of the social economy, the aging of the population, and an increase in both the number of groups with disabilities and the various public health initiatives, there has also been an increase in the awareness of not only the general public but also the government of opportunities within the rehabilitation sector. This trend is clearly related to the rapid development of both China's social economy and its medical reform policies.

The growth rate of the total rehabilitation workforce was lower than that of other selected rehabilitation resources. Furthermore, the personnel density of rehabilitation institutions for PDs has decreased by almost $10 \%$ compared to five years ago. Together, these data indicate that the focus on rehabilitation for PDs may be more concentrated on property, infrastructure, and projects, particularly as investment and rehabilitation resources have increased significantly. In addition, because of the new round of health system reforms enacted in 2009 , the growth in health spending has also increased rapidly to support the development of the rehabilitation sector.

This study explored trends, density, distribution, and equity analysis using data from 2014 to 2019 with data from the CDPF. Based on the results of this study, we found that the overall fairness of rehabilitation resource allocation has improved in China. However, further results for the distribution of rehabilitation resources per 10,000 RPDs and per 10,000 $\mathrm{km}^{2}$ show that there was a large gap between different provinces and regions. Furthermore, there was a larger disparity in the geographic distribution of rehabilitation resources than in the distribution of RPDs. With respect to existing research on health resources [27], this study is unique, as few studies are concerned with this specific area of research.

The value for staff or professionals of rehabilitation institutions showed a downward trend regarding density (both per 10,000 RPDs and per 10,000 $\mathrm{km}^{2}$ ), and the increasing rates were lower than RPDs. There are three reasons for this finding. First, compared to international training of rehabilitation professionals, China only started systematic rehabilitation education after 2001, and the 
educational level was mainly focused on vocational or college education. The university major of rehabilitation therapy was not divided into specific professional directions, such as physical therapy, occupational therapy, and speech therapy. Thus, the rehabilitation workforce entering the job market is limited, including rehabilitation institutions for PDs. Second, there is no professional certification system; professionals, such as rehabilitation therapists, cannot practice as medical practitioners. Third, the general public has a low perception of the occupation and regards it as similar to "massage", leading to low career attraction and high turnover. However, the government has recognized these challenges by expanding higher education on rehabilitation [28]. The University of Rehabilitation is being established in Qingdao, Shandong province, eastern China. Indeed, the higher is the standardized education, the more attractive is the occupation.

The difference in the geographic and demographic density of rehabilitation resources will inevitably lead to an imbalance in rehabilitation resource access for PDs; therefore, we also calculated the HRDI to analyze the comprehensive density in each unit in 2018. The results indicate that there was a comprehensive gap between different provinces and municipalities. Shanghai ranked first in HRDI for all indicators, except for projects of RSFs for PDs. Although rehabilitation resources are related to economic development, it is possible that the concentration of the government or the regional Disabled Person's Federation is more important: this would explain why some eastern provinces were low-ranking. Moreover, there were many more regional gaps and disparities among the three regions: the eastern region's HRDIs of all indicators were on average 2.7 and 4.7 times higher than those of the central and western regions, respectively. At the same time, the central region was 1.9 times higher than the western region.

However, are the rehabilitation resources fair? The results of the Theil Index show that the national Theil Index value has been decreasing annually, which implied that there was better equity within China; however, the highest rate value was found in the projects of RSFs for PDs in 2017 (0.55). The results are not surprising given that the projects, construction area, and investment goals are relatively easy to achieve compared to workforces whose employees require a long training period. However, as the rehabilitation sector for PDs is to some extent a part of public welfare, rehabilitation resources should be allocated scientifically and without bias. Another finding indicates that the causes of inequality in the eastern, central, and western regions principally came from the within-group rather than between-group rate. Compared to health resources, the Theil Index values of rehabilitation resources were higher; however, health resources, such as doctors, experienced the same declining trend during the same time period [16]. The level of economic development and amount of rehabilitation resources in the eastern provinces, such as Shanghai, Beijing, Tianjin, Guangdong, Jiangsu, and Shandong, were much higher than in other provinces. There were more projects per 10,000 RPDs in Fujian (eastern region) and project investment per 10,000 RPDs in Ningxia (western region) than indicated in other areas. Another interesting phenomenon is that the Theil Index showed that the contribution rate among these groups was around $70-75 \%$, thus indicating that unfairness is mainly due to the within-group rate.

As a result, policy makers should focus on the allocation of rehabilitation resources and guide policy in weak provinces in the central and western regions to achieve overall coordinated development for improving access to rehabilitation services for PDs. Our suggestions are as follows: First, the rehabilitation sector should receive more investment. Second, all levels of rehabilitation education should be expanded. Third, the rehabilitation-related statistics system should be further improved, including by inserting it into the national statistics system. Fourth, the government should motivate the market to boost careers in rehabilitation for PDs. Fifth, accreditation of education and regulation of the rehabilitation workforce should be standardized. Sixth, national and sub-national plans regarding the allocation of rehabilitation resources should be created or inserted into a multi-level plan, such as the 14th Five-Year Plan. Finally, the rehabilitation system should be developed and improved within the existing health system. Only in this way can we achieve the goals of Healthy China 2030, Universal Health Coverage, and of SDG3. 
Although this study specifically described the data of rehabilitation resources from 2014 to 2019 , there are some limitations of this data source. Due in part to the data content and indicators having changed in recent years, some data in this study were predicted and estimated, and, furthermore, provincial analysis was only available for a specific period of time. Thus, there is some undue influence on the results. In addition, to discuss the rehabilitation resources for PDs, we used RPDs as the population, weighted on density and the Theil Index analysis. The actual number of potential PDs may be far higher than the RPDs. Moreover, unlike hardware, such as investment and projects, which could be improved in a short period of time, human resources (i.e., the workforce) are key for rehabilitation services and require a longer period of time to be cultivated and trained. Therefore, our next study will continue to follow the updated data from the CDPF. The important results have inspired further analysis on the allocation of human resources for the rehabilitation of PDs, and the rehabilitation resources require evaluation: these areas could represent a future avenue for research.

\section{Conclusions}

The density and equity of rehabilitation resource allocation has improved markedly in recent years. Compared to the four other indicators in this study, staffs and professionals in RIs for PDs demonstrated lower density and equity in all regions. The distribution of accumulated projects completed of RSFs was found to be the most inequitable when compared to the other five types of rehabilitation resources. Regional disparities were typically caused by differences within the regions. As the population ages and the number of disabilities expands, the need for rehabilitation will only continue to increase. The inequality phenomenon might be caused by various factors; thus, we could not make perfectly accurate measurements and assessments of fairness via one kind of tool or unilateral indices. However, we hope that this study can draw attention to the rehabilitation aspect of PDs to improve their access to basic and necessary services.

Author Contributions: Q.J. and Q.T., conceived the study, analyzed the data, and drafted the manuscript; G.C. and J.L., contributed to the study design and supervised and joined the data collection; and X.L. and M.S., gave advice on the statistical analysis and data processing and offered comments to modify of manuscript. All authors have read and agreed to the published version of the manuscript.

Funding: This research was funded by the Major Project of National Social Science Foundation of China (Grant No. 17ZDA078), National Natural Science Foundation of China (Grant No. 71774030 and No. 72004165), Policy Research Project of Shanghai Municipal Health Commission (Grant No. 2020HP21), and Shandong Social Science Planning Fund Program (Grant No. 19CQXJ12 and No. 20CSHJ04). The funders had no role in the study design, data collection and analysis, decision to publish, or preparation of the manuscript.

Acknowledgments: We thank Yugang Li, Xichen Wang, Ke Yan, and Baosong Liu for their help and advice.

Conflicts of Interest: The authors declare no conflict of interest.

\section{Abbreviations}

$\begin{array}{ll}\text { SDGs } & \text { Sustainable Development Goals } \\ \text { PD } & \text { Persons with Disabilities } \\ \text { CRPD } & \text { Convention on the Rights of Persons with Disabilities } \\ \text { CDPF } & \text { China Disabled Persons' Federation } \\ \text { RPD } & \text { Registered Persons with Disabilities } \\ \text { RI } & \text { Rehabilitation Institution } \\ \text { RSF } & \text { Rehabilitation Service Facility }\end{array}$

\section{References}

1. Disability and Health. Available online: https://www.who.int/news-room/fact-sheets/detail/disability-andhealth (accessed on 16 January 2018).

2. Noncommunicable Diseases. Available online: https://www.who.int/news-room/fact-sheets/detail/ noncommunicable-diseases (accessed on 1 June 2018). 
3. Global Health and Aging. Available online: https://www.who.int/ageing/publications/global_health.pdf (accessed on 16 December 2019).

4. Rehabilitation in Health Systems: Guide for Action. Available online: https://apps.who.int/iris/bitstream/ handle/10665/325607/9789241515986-eng.pdf?ua=1 (accessed on 8 May 2020).

5. Ohl, M. Health in all policies case studies. Progressing the sustainable development goals through health in all policies: Case studies from around the world, Lin, Vivian Kickbusch, Ilona. Health Promot. J. Aust. 2019, 30, 292. [CrossRef]

6. United Nations. Policy Brief: A Disability-Inclusive Response to COVID-19; The United Nations: New York, NY, USA, 2020; pp. 1-18.

7. Convention on the Rights of Persons with Disabilities (CRPD) Article 25 . Available online: https://www.un.org/development/desa/disabilities/convention-on-the-rights-of-persons-withdisabilities/article-25-health.html (accessed on 3 July 2020).

8. Hou, X.; Li, S.; Wang, Q. Financial structure and income inequality: Evidence from China. Emerg. Mark. Financ. Trade 2018, 54, 359-376. [CrossRef]

9. China Economic Net. Zhang Yi: Population Growth Slows and Urbanization Continues to Improve. Available online: http://www.stats.gov.cn/tjsj/zxfb/202001/t20200119_1723767.html (accessed on 1 July 2020).

10. Jing, Q.; Qiu, Z.; Ji, L.; Ma, G.; Li, W.; Wang, P.; Sheng, H.; Zheng, W.; Ma, A.; Li, A.; et al. Quantitative and structural analysis of professionals in the institutions affiliated to system of China Disabled Persons' Federation. Chin. J. Rehabil. Theory Pract. 2018, 24, 975-979. (In Chinese)

11. Saadi, A.; Kanmanthareddy, A.; Anantha-Narayanan, M.; Hardy, K.; Williams, M.; Alla, V.M. Access to smart devices and utilization of online health resources among older cardiac rehabilitation participants. World J. Cardiol. 2020, 12, 203-209. [CrossRef]

12. Heine, M.; Lupton-Smith, A.; Pakosh, M.; Grace, S.L.; Derman, W.; Hanekom, S.D. Exercise-based rehabilitation for major non-communicable diseases in low-resource settings: A scoping review. BMJ Global Health 2019, 4, e001833. [CrossRef]

13. Joshi, M. Rehabilitation in Low-Resource Areas. Phys. Med. Rehabil. Clin. N. Am. 2019, 30, 835-846. [CrossRef]

14. Wang, N.; Albaroudi, A.; Chen, J. Decomposing urban and rural disparities of preventable ED visits among patients with Alzheimer's disease and related dementias: Evidence of the availability of health care resources. J. Rural. Health 2020. [CrossRef]

15. El Arnaout, N.; Chehab, R.F.; Rafii, B.; Alameddine, M. Gender equity in planning, development and management of human resources for health: A scoping review. Hum. Resour. Health 2019, 17, 52. [CrossRef]

16. Cao, X.; Bai, G.; Cao, C.; Zhou, Y.; Xiong, X.; Huang, J.; Luo, L. Comparing regional distribution equity among doctors in China before and after the 2009 Medical Reform Policy: A data analysis from 2002 to 2017. Int. J. Environ. Res. Public Health 2020, 17, 1520. [CrossRef]

17. Akbari Sari, A.; Rezaei, S.; Homaie Rad, E.; Dehghanian, N.; Chavehpour, Y. Regional disparity in physical resources in the health sector in Iran: A comparison of two time periods. Iran J. Public Health 2015, 44, 848-854.

18. Zhu, D.; Shi, X.; Nicholas, S.; He, P. Regional disparities in health care resources in traditional Chinese medicine county hospitals in China. PLoS ONE 2020, 15, e0227956. [CrossRef] [PubMed]

19. Ravaghi, V.; Farmer, J.; Quiñonez, C. Persistent but narrowing oral health care inequalities in Canada from 2001 through 2016. J. Am. Dent. Assoc. 2020, 151, 349-357.el. [CrossRef] [PubMed]

20. Wang, S.; Xu, J.; Jiang, X.; Li, C.; Li, H.; Song, S.; Huang, E.; Meng, Q. Trends in health resource disparities in primary health care institutions in Liaoning Province in Northeast China. Int. J. Equity Health 2018, 17, 178. [CrossRef] [PubMed]

21. Wang, Y.Y.; Li, Y.Y.; Qin, S.R.; Kong, Y.F.; Yu, X.Y.; Guo, K.Q.; Meng, J.Y. The disequilibrium in the distribution of the primary health workforce among eight economic regions and between rural and urban areas in China. Int. J. Equity Health 2020, 19, 28. [CrossRef] [PubMed]

22. Liu, W.; Liu, Y.; Twum, P.; Li, S. National equity of health resource allocation in China: Data from 2009 to 2013. Int. J. Equity Health 2016, 15, 68. [CrossRef] [PubMed]

23. Camporeale, R.; Caggiani, L.; Fonzone, A.; Ottomanelli, M. Study of the accessibility inequalities of cordon-based pricing strategies using a multimodal Theil index. Transp. Plan. Technol. 2019, 42, 498-514. [CrossRef] 
24. Sarabia, J.M.; Jordá, V.; Remuzgo, L. The Theil indices in parametric families of income distributions: A short review. Rev. Income Wealth 2016, 63, 867-880. [CrossRef]

25. Liu, X.; Yang, X.; Guo, R. Regional differences in fossil energy-related carbon emissions in China's eight economic regions: Based on the Theil index and PLS-VIP method. Sustainability 2020, 12, 2576. [CrossRef]

26. Rój, J. Inequality in the distribution of healthcare human resources in Poland. Sustainability 2020, $12,2043$. [CrossRef]

27. Zhang, Y.; Wang, Q.; Jiang, T.; Wang, J. Equity and efficiency of primary health care resource allocation in mainland China. Int. J. Equity Health 2018, 17, 140. [CrossRef]

28. Ying, L.; Fengqing, W.; Qing, W.; Ming, X.; Liping, D. Current situation and training pathway exploration for high-level staff in rehabilitation therapy. Chin. J. Med. Educ. 2019, 39, 207-210. (In Chinese)

(C) 2020 by the authors. Licensee MDPI, Basel, Switzerland. This article is an open access article distributed under the terms and conditions of the Creative Commons Attribution (CC BY) license (http://creativecommons.org/licenses/by/4.0/). 